\title{
Role of Morphometry of Placenta in Determination of Birth Weight of Fetus in Hypertensive Mothers
}

\author{
Yousuf Begum ${ }^{\circledR 1}$, Syeda Ayesha Fatima ${ }^{\circledR 2}$, Syeda Khadija Fatima ${ }^{\circledR 3}$ \\ ${ }^{1}$ Assistant Professor, Department of Anatomy, College of Medicine, Imam Abdulrahman Bin Faisal University, Dammam, KSA, Saudi Arabia, ${ }^{2}$ Assistant Professor, \\ Department of Pharmacology, Apollo Institute of Medical Sciences and Research, Jubilee Hills, Hyderabad, Telangana, India, ${ }^{3}$ Assistant Professor, Department of \\ Pathology, Kamineni Institute of Medical Sciences, Nalgonda, Telangana, India.
}

\section{Abstract}

Background: The present study was conducted to assess the association of morphometry of the placenta and birth weight of fetus in hypertensive mothers. Subjects and Methods: The present study was conducted on 74 pregnant women with an uncomplicated pregnancy and those with pregnancy-induced hypertension (PIH). The following morphometric parameters of each placenta were recorded: weight, volume, thickness, transverse diameter, and shape. Gestational age of mothers, sex and birth weight of newborns were recorded. Results: The majority of male babies with weight $>2500$ grams had $>37$ weeks of gestational age and the majority of female babies with weight $>2500$ grams had $>37$ weeks of gestational age. The mean weight of placentae in male babies was 416.7 grams, the mean surface area was $226.5 \mathrm{sq} \mathrm{cm}$, mean volume was 372.2 $\mathrm{ml}$ and mean thickness were $2.04 \mathrm{~cm}$. while the mean weight of placentae in female babies was 407.5 grams, the mean surface area was $220.4 \mathrm{sq}$ $\mathrm{cm}$, mean volume was $354.6 \mathrm{ml}$ and mean thickness was $2.10 \mathrm{~cm}$. Statistics show that the highest sensitivity and specificity for determining the low birth weight of babies in hypertensive mothers was seen with a surface area of the placenta which was $82.3 \%$ and $75.6 \%$ respectively. The positive predictive value for the weight of the placenta was $65.4 \%$, for the surface area it was $67.8 \%$ and for the volume of the placenta, it was $64.2 \%$. Conclusion: To conclude, it was found that placental morphometry like weight, surface area, volume and sex of the baby determined the birth weight efficiently in hypertensive mothers.

Keywords: Birth weight, Hypertension, Placenta

Corresponding Author: Yousuf Begum, Assistant Professor, Department of Anatomy, College of Medicine, Imam Abdulrahman Bin Faisal University, Dammam, KSA, Saudi Arabia.

E-mail: ybegum@iau.edu.sa

Received: 30 October 2020

Revised: 18 November 2020

Accepted: 25 November 2020

Published: 22 December 2020

\section{Introduction}

The term placenta was derived from the flat cake in Latin. ${ }^{[1]}$ The placenta represents a fusion of uterine mucosa to fetal membranes for the transfer of oxygen and other metabolic products between fetal and maternal blood. ${ }^{[2]}$ It helps in supplying oxygen, nutrients and protection to the fetus beside it's endocrine and secretory function. ${ }^{[1,3-5]}$ One of the major causes of maternal and neonatal morbidity and mortality is pregnancy-induced hypertension. This specific disorder was recognized since the time of Hippocrates and until now delivery of the placenta remains the only completely successful therapy. Though a microscopic examination of the placenta is useful to determine the nature of the pathology, it does not show specific features.

Fetal well-being is affected by many factors, but a healthy placenta is one of the most important factors in producing a healthy baby. The outcome of pregnancy depends on the morphometry of the placenta, and its ability to transfer nutrients, gases, waste products, heat, hormones, and other regulatory molecules. It also prevents the rejection of the fetal allograft. The placental blood flow, morphology and its transport functions determine the trajectory of growth of the fetus. ${ }^{[3-9]}$

The changes in the chorionic surface area affect the birth weight of babies. When compared to male babies the female babies birth weight and their fetoplacental ratio (FPR) are more responsive to these changes in chorion as a result of greater female resilience and male vulnerability to gestational stresses. ${ }^{[8]}$ Hence, all the variables of placental morphometry affect fetal growth in a different manner in male and female babies. Many studies have been done on placental weight in relation to birth weight of newborn and on fetoplacental ratio. ${ }^{[9-11]}$ The present study was conducted to assess the 


\begin{tabular}{|c|c|c|c|}
\hline \multirow[t]{2}{*}{$\begin{array}{l}\text { Birth } \\
\text { weight }\end{array}$} & \multicolumn{2}{|c|}{$\begin{array}{l}\text { Gestation age (Male group } \\
\text { ) }\end{array}$} & \multirow[t]{2}{*}{ Total } \\
\hline & $<37$ weeks & $>37$ weeks & \\
\hline$<2500$ & 13 & 10 & 23 \\
\hline$>2500$ & 7 & 12 & 19 \\
\hline Total & 20 & 22 & 42 \\
\hline \multicolumn{4}{|c|}{ Gestational age (Female group) } \\
\hline & $<37$ weeks & $>37$ weeks & \\
\hline$<2500$ & 5 & 9 & 14 \\
\hline$>2500$ & 7 & 11 & 18 \\
\hline Total & 12 & 20 & 32 \\
\hline
\end{tabular}

correlation between morphometry of the placenta and birth weight of the fetus.

\section{Subjects and Methods}

The present study was conducted in the Department of Anatomy, in a teaching medical college and hospital in Hyderabad, Telangana, India. In the present study, 74 pregnant women with an uncomplicated pregnancy and those with pregnancy-induced hypertension (PIH) were selected. All were informed regarding the study and data such as names, age, parity, vitals etc., was recorded, after obtaining their written consent. The study was approved by the institutional ethical committee.

After delivery, the placenta was collected immediately for macroscopic and microscopic studies. The following parameters of each placenta were recorded: weight, volume, thickness, shape, transverse diameter, surface area. The water displacement method was used to measure the volume of the placenta, the thickness was measured by inserting a calibrated knitting needle at the center of the placenta, the weight of the placentae was recorded in grams with the help of scientific balance. Placenta from all deliveries was examined grossly, for the feature of membranes, site of insertion of the umbilical cord, calcification, presence of infarction, and retroplacental hematoma. Gestational age, birth weight and sex of newborns were recorded. Results were tabulated and subjected to statistical analysis. A P-value of less than 0.05 was considered significant.

\section{Results}

[Table 1] shows that the majority of male babies with weight $>$ 2500 grams had $>37$ weeks of gestational age and the majority of female babies with weight $>2500$ grams had $>37$ weeks of gestational age.

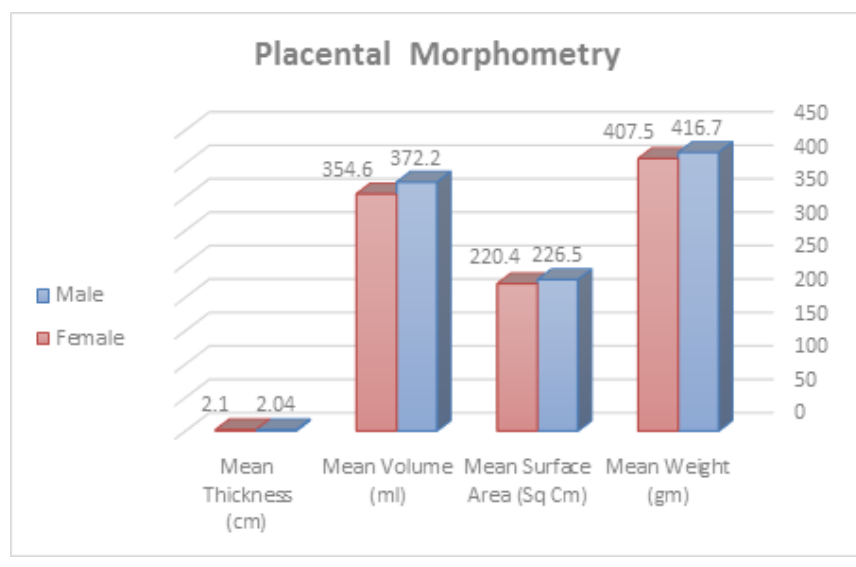

Figure 1:

[Table 2] shows that in the placenta of male babies: the mean weight was 416.7 grams, the mean surface area was $226.5 \mathrm{sq}$ $\mathrm{cm}$, mean volume was $372.2 \mathrm{ml}$ and mean thickness was 2.04 $\mathrm{cm}$, whereas in the placenta of female babies: the mean weight was 407.5 grams, the mean surface area was $220.4 \mathrm{sq} \mathrm{cm}$, mean volume was $354.6 \mathrm{ml}$ and mean thickness was $2.10 \mathrm{~cm}$.

[Figure 1] Shows that measurements of placental morphometry: mean weight, mean surface area, mean volume, and mean thickness of placenta in male babies were higher compared to the similar measurement of the placenta in female babies.

[Table 3] Statistics show that the highest sensitivity and specificity for determining the low birth weight of babies in hypertensive mothers was seen with a surface area of the placenta which was $82.3 \%$ and $75.6 \%$ respectively. The positive predictive value for the weight of the placenta was $65.4 \%$, for the surface area it was $67.8 \%$ and for the volume of the placenta, it was $64.2 \%$.

\section{Discussion}

In the present times, the number of cases of pregnancy-induced hypertension is increasing mostly due to stress, change in the lifestyle of Indian women, and an increase in maternal age. For an anatomist, it is important to know the gross changes in the placentae of hypertensive women compared to the normal ones. ${ }^{[12]}$ Being a crucial organ in pregnancy, many gynecologists and obstetricians are studying the placenta since the last century about its weight and surface area. ${ }^{[13]}$ Toxemia of pregnancy is the leading cause of maternal mortality and is an important factor in fetal loss. Due to prevailing malnutrition, hypoproteinemia, and poor obstetric facilities incidence of fetal loss is high in developing countries. ${ }^{\left[{ }^{[114]}\right.}$ The present study was conducted to assess how morphometry of the placenta affects the birth weight of the newborn. 
Table 2: Placental morphometry in low birth weight groups.

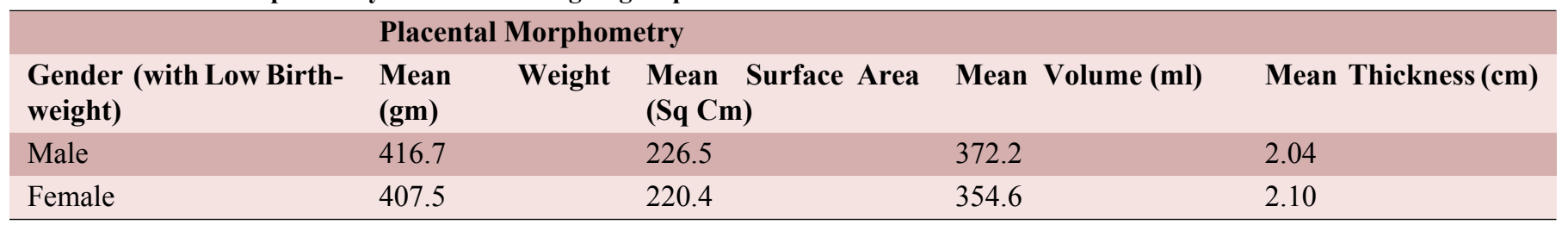

Table 3: Sensitivity and specificity of regression models to estimate low birth weight using placental morphometry and sex

\begin{tabular}{llll}
\hline Constants & Placental Morphometry & Volume \\
\hline Sensitivity & Weight & Surface area & 75.4 \\
Specificity & 76.2 & 82.3 & 73.1 \\
\hline Positive Predictivity & 74.3 & 75.6 & 64.2 \\
\hline Negative Predictivity & 65.4 & 67.8 & 81.3 \\
\hline
\end{tabular}

Balihallimath et al, ${ }^{[11]}$ conducted a study on 164 consecutive singleton deliveries and found that gestational age exhibited a positive relationship with birth weight. In the present study, similar to Balihallimath et al there is a positive relationship between gestational age and birth weight as seen in [Table 1], the majority of male babies with weight $>2500$ grams had $>$ 37 weeks of gestational age and the majority of female babies with weight $>2500$ grams had $>37$ weeks of gestational age.

Placental parameters showed a positive and significant relationship $(\mathrm{p}<0.001)$ with birth weight and higher values in males. The birth weight was estimated by regression models using sex of the newborn and placental morphometry; weight $(\mathrm{R} 2=0.474)$, surface area $(\mathrm{R} 2=0.420)$, and volume $(\mathrm{R} 2=0.477)$ at $95 \%$ confidence interval. Low birth weight babies in the study were correctly identified by placental weight, surface area, volume, and sex of the newborn. Their sensitivity, specificity and predictive values have been specified.

We found that the mean weight of the placenta of male babies was 416.7 grams, the surface area was $226.5 \mathrm{sq} \mathrm{cm}$, volume was $372.2 \mathrm{ml}$ and thickness was $2.04 \mathrm{~cm}$. The mean weight of the placenta of female babies was 407.5 grams, the surface area was $220.4 \mathrm{sq} \mathrm{cm}$, volume was $354.6 \mathrm{ml}$ and thickness was $2.10 \mathrm{~cm}$, shown in [Table $2 \&$ Figure1].

Kambale et al, ${ }^{[15]}$ studied ninety placentae, where he studied the weight of the placenta, placental fetal ratio, macroscopic and histopathological findings. Placental findings were correlated with fetal outcome. In a hypertensive group, there was a reduction in the placental weight and fetoplacental weight ratio $(5.38: 1)$ while there was an increase in the incidence of retroplacental hematoma (15.5\%) and infarction $(28.8 \%)$. It was concluded that hypertensive conditions influence placental morphology. The poor fetal outcome is observed in the presence of gross features like retroplacental hematoma and infarction. The perinatal outcome is adversely influenced by the pathological changes observed in the placentae of patients with hypertensive disorders of pregnancy.

We observed that the positive predictive value for the weight of the placenta was $65.4 \%$, for the surface area was $67.8 \%$ and for the volume of the placenta was $64.2 \%$, as shown in [Table $3]$. Wallace analyzed that the placental weight and FPR were reported higher in males as compared to females, similar to our study. ${ }^{[16]}$

\section{Conclusion}

Authors conclude that placental morphometry like weight, surface area, volume and sex of the newborn baby determines the birth weight efficiently in hypertensive mothers.

\section{References}

1. Joshi VV. Handbook of Placental Pathology. Igaku Shoin Medical Publisher. 1994;

2. Avasthi K, Micha U. Histopathology of placenta and it's correlation with fetal outcome. J Obstet Gynecol India. 1991;41:317-345.

3. van den Broek N, Ntonya C, Kayira E, White S, Neilson JP. Preterm birth in rural Malawi: high incidence in ultrasounddated population. Human Reproduction. 2005;20(11):32353237. Available from: https://dx.doi.org/10.1093/humrep/ dei208.

4. Anthony RV, Scheaffer AV, Wright CD, Regnault TR. Ruminant models of renatal growth restriction. Reproduction Suppl. 2003;61:183-94.

5. Salafia CM, Charles AK, Maas EM. Placenta and Fetal Growth Restriction. Clin Obstet Gynecol. 2006;49(2):236256. Available from: https://dx.doi.org/10.1097/00003081200606000-00007. 
6. Baptiste-Roberts K, Salafia CM, Nicholson WK, Duggan A, Wang NY, Brancati FL. Maternal risk factors for abnormal placental growth: The national collaborative perinatal project. BMC Pregnancy Childbirth. 2008;8(1):44-44. Available from: https://dx.doi.org/10.1186/1471-2393-8-44.

7. Brett K, Ferraro Z, Yockell-Lelievre J, Gruslin A, Adamo K. Maternal-Fetal Nutrient Transport in Pregnancy Pathologies: The Role of the Placenta. Int J Mol. 2014;15(9):16153-16185. Available from: https://dx.doi.org/10.3390/ijms150916153.

8. Misra DP, Salafia CM, Miller RK, Charles AK. Non-Linear and Gender-Specific Relationships Among Placental Growth Measures and The Fetoplacental Weight Ratio 2 Placenta. 2009;30(12):1052-1057. Available from: https://dx.doi.org/10. 1016/j.placenta.2009.09.008.

9. Scherle WF. A simple method for volumetry of organ in quantitative stereology. Mickroskopie. 1970;26:57-60.

10. Blake KV, Gurrin LC, Beilin LJ, Stanley FJ, Landau LI, Newnham JP. Placental weight and placental ratio as predictors of later blood pressure in childhood. J Hypertens. 2001;19(4):697-702. Available from: https://dx.doi.org/10. 1097/00004872-200104000-00006.

11. Balihallimath RL. Placental Morphometry Determines the Birth Weight. J Clin Diagn Res. 2013;7(11):2428-2431. Available from: https://dx.doi.org/10.7860/jcdr/2013/7478.3564.

12. Salge AK, Rocha KM, Xavier RM, Ramalho WS, Rocha EL, Guimaraes JV, et al. Macroscopic placental changes associated with fetal and maternal events in diabetes mellitus. Clinics. 2012;67(10):1203-1208. Available from: https://dx.doi.org/10. 6061/clinics/2012(10)13.

13. Bleker OP, Buimer M, Post JAVD, Veen FVD, (g JT. Ted (G.J.) Kloosterman: on intrauterine growth. The significance of pre- natal care. Studies on birth weight, placental weight and placental index. Placenta. 2006;27(11-12):1052-1054. Available from: https://doi.org/10.1016/j.placenta.2006.01.001.

14. Ghodke S, Dharwadkar S. Hypertensive disorders affecting the morphometry of placenta. J Sci Soc. 2012;39(1):17-17. Available from: https://dx.doi.org/10.4103/0974-5009.96464.

15. Iqbal B, Kambale T, Ramraje S, Swaimul K, Salve S. Placental morphology and fetal implications in pregnancies complicated by pregnancy-induced hypertension. Med J DY Patil Vidyapeeth. 2016;9(3):341-341. Available from: https: //dx.doi.org/10.4103/0975-2870.182505.

16. Wallace JM, Bhattacharya S, Horgan GW. Gestational age, gender and parity specific centile charts for placental weight for singleton deliveries in Aberdeen, UK. Placenta. 2013;34(3):269-274. Available from: https://dx.doi.org/10. 1016/j.placenta.2012.12.007.

Copyright: (C) the author(s), 2020. It is an open-access article distributed under the terms of the Creative Commons Attribution License (CC BY 4.0), which permits authors to retain ownership of the copyright for their content, and allow anyone to download, reuse, reprint, modify, distribute and/or copy the content as long as the original authors and source are cited.

How to cite this article: Begum Y, Fatima SA, Fatima SK. Role of Morphometry of Placenta in Determination of Birth Weight of Fetus in Hypertensive Mothers. Acad. Anat. Int. 2020;6(2):77-80.

DOI: dx.doi.org/10.21276/aanat.2020.6.2.17

Source of Support: Nil, Conflict of Interest: None declared. 